\title{
15. Playing with politics: Memory, orientation, and tactility
}

\author{
Sam Hind
}

\begin{abstract}
The focus of this chapter is how playfulness can be a constitutive part of political activism. Analyzing the anti-austerity demonstrations in London in 2011, Hind looks at the carnivalesque and ludic qualities during the March for the Alternative, which attracted over 250,000 protesters. One of the highlights of this march was a giant Trojan horse that people carried with them. In Hind's analysis, ludic political interventions such as the Trojan horse constitute a playful, material, and performative relationship between digital technologies and embodied political actions. Hind draws attention to the fact that political events are not solely human-driven, but that technologies form an intrinsic part of how they unfold. Through a reading of Stiegler, he examines the material and affective dynamics of contemporary protest events.
\end{abstract}

Keywords: Political activism, ludic interventions, the carnivalesque, mobility

In this chapter, I want to propose that protest events are not solely humandriven. Although this might seem a rather modest task to undertake, it is a rather bold proposition. Think of the affective nature of all manner of demonstrations, rallies, marches, occupations, and even riots. Think also of the objectives. Protest events are designed to change human thinking and acting. Some are anti-war campaigns to rally fellow citizens. Others are full-scale revolutions designed to shift power from autocratic leaders to the people. In essence, they might be witnessed as wholly human accomplishments.

Glas, R., S. Lammes, M. de Lange, J. Raessens, and I. de Vries, eds. 2019. The Playful Citizen. Civic Engagement in a Mediatized Culture. Amsterdam: Amsterdam University Press. DOI: 10.5117/9789462984523/CH15 
But what is often missing from accounts of these moments is a nuanced consideration of the role of technology. Although it is now commonplace to suggest that social media has become a conduit for organization of, and solidarity with, demonstrations the world over, it is less common to chart these technologies in action. Platform-specific messages do not necessarily invoke a change in thinking. Nor do they magically cause citizens to assemble. While a tweet, a Facebook notification, or a Firechat message may stimulate action this cannot be presumed in advance of its happening. What is of interest in this chapter is how platform-specific messages affect the playful, material, and performative dimensions of protest events. In order to situate this, I will first provide a brief introduction to social media and protest. Then, I will turn to Bernard Stiegler $(1998,2009)$ and his work on the mnemotechnical and navigational developments in contemporary society. In other words, I will examine his work to address the importance of memory and orientation. To these I will also add a discussion on the tactile nature of protest events to draw out the more recent shifts at the interface between technology and protest.

In order to show the specificity of these dynamics I will make reference to one particular incident; the parading of a Trojan Horse that took place during an anti-austerity demonstration in London, on 26 March 2011. Organized by the umbrella organization, the Trades Union Congress (TUC), it was known as the March for the Alternative, and attracted over 250,000 protesters (BBC News 2011) — including myself. Photographic evidence and contributions from social media collected both during and after the event will serve as the empirical basis for this contribution. The playful, material, and performative relation between the Trojan Horse and digital technology will become clearer as this chapter proceeds.

\section{Social media and protest: The delusional citizen?}

Although some may wager that the exercise of rights now takes place quite at the expense of bodies on the street, that Twitter and other virtual technologies have led to a disembodiment of the public sphere, I disagree. - Butler (2011, n.p.)

As Juris (2012) points out, network-based forms of social movement organization are nothing new. The New Social Movements of the 1970 s were characterized by less hierarchical arrangements of command that were not predicated upon a centralized organizational form (Buechler 1995). Protestors 
have also been using forms of digital communication to coordinate action since the late 1990s. The global justice movement utilized listserve networks during this period to communicate with followers across the world. They allowed computer users from disparate locations to connect with the cause of global justice. But, as Juris $(2012,260)$ further contends, this was far from a revolutionary overhaul in organization, but more simply an incorporation of new forms of media into "ongoing practices of core groups of activists," with the aim to "diffuse new dynamics of activism."

Fast-forward, and the mobilization of activists via Twitter during the various Occupy protests (see Constanza-Chock 2012; Pickerill and Krinsky 2012; Gleason 2013) is but a more recent example of the entanglement of such events with new technological capabilities. Again, it is important to note that although such advances in access to (and speed, performance, and mobility of) such technologies are undoubtedly contributing to a radical shift in protest operation, there are still a number of caveats. While it may seem that access is open and universal to social media platforms such as Twitter, divides do remain. Geography, class, age, race, and gender continue to be barriers to online participation (see Zook and Graham 2007; Crutcher and Zook 2009; Thatcher 2013), suggesting that the infrastructural, social, and political bases for contribution are highly uneven - this despite widespread discussion on the 'democratization' of data in the 'Web 2.0' era (Morozov 2011; Haklay 2013).

Moreover, the efforts of groups such as Anonymous and Lulzsec (Gallagher and Arthur 2011), while synonymous with more natively digital protests such as hacks and distributed denial-of-service (DDoS) attacks, have also spawned collective, urban action (Gekker, see Chapter 20 in this volume). The widespread use of Guy Fawkes masks made popular in the Vfor Vendetta film (McTeigue 2005) during the Occupy protests was a striking example of the visible solidarity between contemporary protesters (see Elden 2011). This is what the journalist Jonathan Jones has called a kind of 'festive citizenship' (Jones 2011); drawing on the public image of an amorphous hacktivist group to re-constitute the carnivalesque in a new technological age (see Sicart 2014, 10-11).

Gerbaudo $(2012,2)$ explicitly asked: "Is this all just an activist delusion?" In other words, can we really draw causal links between social platform content and on the ground action? Are the dynamics outlined above really constitutive of a new arena of civic engagement? Or do they constitute a kind of technological fetishism in which a causal link between message and action is presumed a priori? The next three sections will draw out the parameters of the debate by drawing on the work of Bernard Stiegler (1998, 
2009). Social media, it is argued here, are used in three ways to stimulate action on the ground: to form a recallable and recoverable depository of moments within events; to construct a navigational orientation toward moments during events; and to forge a co-constitution of body and action in events.

\section{Memory and event}

One of the ongoing discussions surrounding new technological devices is the effect on the human capacity to remember. Nicholas Carr (2008) theorized in his infamous article 'Is Google making us stupid?' on how Google was helping to shape "the process of thought" by becoming a conduit for information-gathering. This, Carr suggests, is leading to a reduction in people's mental capacity to concentrate, to contemplate, and their ability to engage in deep learning.

Digital devices like personal computers, mobile phones or tablets, or online platforms like Google, Twitter, or Facebook constitute a materialization of thought, or what Bernard Stiegler (1998) terms 'tertiary forms of memory.' These "technical objects," as Stiegler refers to them, sift, collect, store, structure, catalogue, and re-present information exterior to the human body so that thoughts become "inscribed in the non-living body" of technical objects (Stiegler 2009, 4). It is through these objects that we, as humans, are comprised especially in spatial terms as Kinsley (2014) and Ash (2010, 2012) have explored. It is this inscription that becomes a valuable technique for those participating in protest events, as the content of such objects far outlives their producers.

This has implications for what is known as primary and secondary forms of memory. The former constitutes the "original impression" (Stiegler 2009, 246) of an event or a moment; that initial period of perception in which people capture and process everyday occurrences. For instance, at the moment an activist encounters other fellow protesters during a demonstration. The latter forms what we know as human memory; the fragmentation of past experiences constituted in the mind afterwards. Say, in the days, weeks, months, and years after a particularly memorable protest event. These are naturally partial, reconstituted, and re-imagined fragments that together with primary perceptual impressions form 'protensions,' the projection of past thoughts and perceptions into everyday life.

But while primary and secondary memories cease to exist when a life form dies, memories supplanted and registered in digital devices and online 
platforms continue on. Stiegler's (1998) general claim therefore, is that technology acts as a third type of human memory, one that, despite laden with a degree of human knowledge, is nonetheless exterior to, and independent of, human memory. It is for this reason that it becomes a powerful tool during protest events, providing the ability for others to collect, search, and recall particular moments otherwise 'lost.' Moreover, critically, that tertiary forms of memory come to constitute both primary and secondary forms of memory in the first instance. In other words, digital devices and online platforms precede and therefore wholly shape the types of experiences and capacities for thought that Carr (2008) suggested earlier. It is only through tertiary forms of memory - technologies that enable us to store and recover moments - that our primary and secondary forms can function.

Stiegler $(2009,8)$ calls this relationship between tertiary memory, individual, and environment 'mnemotechnics.' Put otherwise, all forms of media - from printed books to social media platforms - allow for a kind of memory to be developed and inscribed. The primary function of this is to reduce the cognitive load on the human. If something becomes inscribed there is little need to remember it in full-it is safe and secure written, drawn, photographed, or copied down in some other way. Such is the power of this material independence that it is capable of outliving all other forms of memory, and evolving in an altogether unique way. However, these dynamics of technical evolution, Simondon (1958/1980) maintains, have been criminally misinterpreted, representing a prosthetic, developmental necessity of human life. By extension we can understand how digital technology within protest events has constituted a prosthesis of action. However, this is not the form of technological fetishism questioned previously. For although Stiegler holds that technology is a prosthetic, developmental necessity of human life, he does not believe that because of this we are married to any specific technology per se. We can still propose the former without slipping into the latter, thus avoiding the technological determinism highlighted by Gerbaudo (2012).

In the conceptualization of a tertiary memory, Stiegler $(2009,12)$ grapples firstly with what he calls "the orthographic age." In constituting the practice of writing as the foremost prosthesis of technical memory, Stiegler is able to comprehend the role technical objects have in shaping and remembering human politics. As he says:

It is philology's business to establish the authenticity of source materials; once they have been established, I no longer doubt having access, as if I were there, to Plato's or Heidegger's orthographic thoughts, constituted in the very possibility of a certain after-the-fact re-constitution. (Ibid., 8) 
We do not question, in everyday matters, the medium of the written word, only the veracity of the message written within. For Stiegler, the words of Plato and Heidegger do two things. In the first instance, they suffice for either two, working as Plato and Heidegger, so that we correlate the words of either as they themselves speaking the very same words. This is despite the existence of any intonation, rhythm, or accent. Not least to mention either authors' physical or mental state that would have had a bearing on how the words were transmitted. Then, in the second instance, they work beyond either author, lasting far longer than either could have imagined or indeed realized. The writings of both Plato and Heidegger thus serve as lingering artefacts of human thought and endure as objects of a technical memory.

One particular moment during the March for the Alternative demonstration exemplifies Stiegler's argument. Consider the photographic evidence of a cumbersome, wood and cloth Trojan Horse crafted and paraded by protesters along the official march route (see Figure 15.1). Its progression was marked by Twitter users as messages were sent and photos uploaded of its whereabouts along the march route. What was particularly interesting was the way in which the Trojan Horse was variously constituted through different, mediated accounts. The protest application Sukey $(2011)^{1}$ was the first to note its presence, tweeting an image from a feeder point in Kennington Park, south of the route (Sukeyio 2011a) along with the message "Fake Stallions Unite." As it made its way into central London, the Metropolitan Police's communication team (CO11) urged protesters to "continue on the march past the Trojan Horse effigy in [sic] Downing Street" (MetPoliceEvents 2011) in order to avoid the demonstration slowing down. But as protesters began to congregate around the unwieldy object, Sukey responded to the Metropolitan Police by satirically suggesting that David Cameron, the UK Prime Minister at that time, could not come out to bring it inside with such a large number of protesters gathered around (Sukeyio 2011b). Meanwhile, in a factual tone, the organizers of the event, the TUC, simply alluded to an "incident at Downing St."

The nature of each communication, as a result, went some way in shaping both the general perception of, and re-action to, the event. If users were to solely take the CO11's account of the Trojan Horse seriously, they might be urged to continue past a jovial expression of public outrage against public

1 Sukey is a "multi-platform, news, communications and logistical support system" (Sukey 2011) for protesters.

2 The tweet in full: "March is held up due to incident at Downing St. \#26march." Retrieved from personal records collected during the event. The account has since been deleted. 


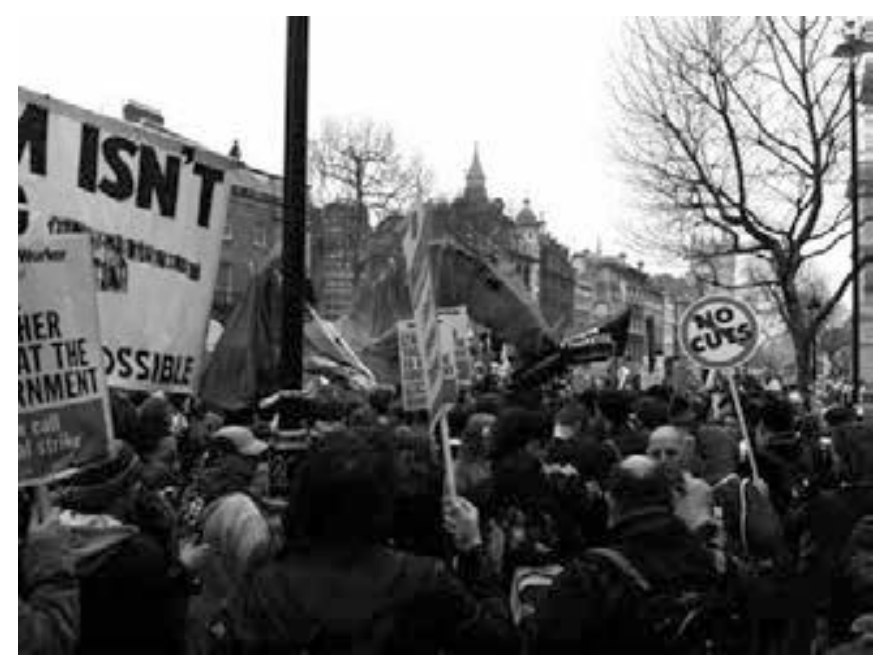

15.1: The Trojan horse at the March for the Alternative, London, UK (Twitter user @smithsam).

sector cuts. If users were entertained by Sukey's take on the incident, they might well have made their own satirical remarks on David Cameron's predicament and joined in the chorus of disapproval. Further still, if fellow Twitter users had taken to the TUC's social media account for updates about the protest, they might well have mistaken the disruption for an unspecified, insignificant, and momentary event. But as Rieder (2012) suggests, some tweets receive more coverage due to their conversational spin on events. The TUC's account is a coded reading intended to avoid conflict. The $\mathrm{CO} 11$ message, however, has an expressive tactical meaning. It is an instruction to move. A command to continue along the pre-designated route at a pre-defined speed. The Sukey account is different again; appealing to the jovial, carnivalesque nature of the protest event. Even though each message has a "refractive capacity" (Rieder 2012, n.p.) to spin, twist, or frame the story, only the Sukey account succeeds in mobilizing it fully. While it is possible to trace back the logistical narrative of the event through the TUC and CO11 accounts, it is a bare, functional story-one devoid of the transgressive nature of protest events and their ability to challenge or at least 'temporarily relieve' (Lane Bruner 2005) oppressive political power. Neither the CO11, nor TUC accounts were set up to facilitate such action and, as such, refrained from providing any kind of spin, other than a rote account of the incident.

If we understand Stiegler correctly, and we are to follow his thesis on mnemotechnics, then we are to say that the Trojan Horse that was paraded around London was a kind of tertiary memory inscribed with the thoughts 
and actions of the people who devised and constructed it. Even within the same media platform - in this case, Twitter - this constructive process has the potential to be markedly different depending on the account of such events. In this way, the Trojan Horse was materially coded, stored, and re-constituted courtesy of the digital medium, this despite its ceremonial burning at the busy road junction hours later. Although the object ceased to exist, it lived on through the platform - remembered and recoverable far beyond the spatio-temporal constraints of the event itself. It is only through these mnemotechnical inscriptions that the event itself is now actually composed; through and prior to all other forms.

\section{Orientation and event}

In the first instance, this refractive capacity concerns a temporal quality: the ability to witness, remember, and spin events. Now I want to move on to the Trojan Horse's navigational character. In other words, I want to consider how those who constructed the Trojan Horse-and I include here the Twitter users and photographers just as much as the joiners and painters of the horse-became key protagonists in constituting the Trojan Horse as a geospatial event itself.

The employment of spatial metaphors throughout the history of the web has helped in conceptualizing its networked infrastructure to unfamiliar users. Discussions on 'cyberspace' were the first to use such terminology during the late 1990s, when it was believed that the cyber-era would overthrow the tyranny of materiality, open up new freedoms and allow for the "unfettered circulation of abstract free-floating information" (Stevenson $2013,45)$. As Nunes $(2006,8)$ suggested, “[t]he 'space' of cyberspace $[. .$. remained firmly within scare quotes" - in cybernetic terms it was meant to be boundless and without physical constraint. But at a time when computers were heavy, immobile, and accessible only in specific places (i.e. internet cafes, libraries, etc.), spatial metaphors had to be mobilized to describe the nature of connections and 'virtual' actions. Desktop computers, chained to the desks of users, would paradoxically act as portals to a boundary-less world. As Graham $(2013,179)$ suggests, "common prepositions associated with internet use (e.g to go to a website, or to get on the Internet) imply a certain spatiality" despite claims in the cyber-era to the contrary. This cyberspace, however ethereal, abstract, and boundless, nevertheless strongly held to spatial metaphors in order to aid users in conceptualizing the types of actions required to engage with such technology. 
However, the interactive nature of the social media era shattered this fixed, singular notion of abstract digital space. Material and digital worlds have forever been inextricably linked (Graham, Zook, and Boulton 2012). Place and space are thoroughly constituted through a relation with the digital. Interactions commonly cross, loop back into, and affect the material world. They augment and, in some cases, completely constitute the make-up of everyday experience. Kitchin and Dodge (2011) have been the most persistent in making this academic argument of the intermingling of code and space, employing Gilbert Simondon's notion of 'transduction' in order to argue for the (spatially) transformative nature of modern technologies (see also MacKenzie 2002; Dodge and Kitchin 2005). Stiegler, also a reader of Simondon, again provides an adequate framework for this understanding.

In Technics and time, 2 Stiegler $(2009,65)$ talks of a "genesis of disorientation." In the first instance, technologies involve a delegation of authority from the who to the what; a delegation that has progressively distanced humans from their own knowledge. As Leroi-Gourhan $(1975,65$ quoted in Stiegler 2009, 78) remarks, this delegation is split into five stages; "of oral transmission, of written transmission with tablets or indices, with simple filing systems, with mechano-graphics, and with electronic seriation." With each advance, Leroi-Gourhan contends, an even greater collective memory is constructed, contributing to the "progressive exteriorization of individual memory" $(1975,65)$. In this ensuing process, the only logical way for humans to then begin to orientate themselves-bearing in mind Stiegler's (1998) earlier claim that humans are always-already constituted through technical objects - is to attempt to articulate the demands of technical evolution. This involves an orientation at two levels.

First, it is an orientation between ethnic knowledges - those constructed by particular cultures at specific times-and technical objects. This is orientation qua memory, covered in the previous section. Second, though, it is a spatiotemporal orientation of rhythmicity. This is an orientation that calls forth the relationship between program (technical object) and speed. Consider, for example, the way in which social media platforms and 24-hour news channels have re-constituted news-making by drawing out and speeding up the news cycle. Central to this argument is the relationship between technical object and space. We can call this orientation a navigational dynamic in order to make this claim more explicit.

As Stiegler has detailed, the evolution of technology (oral, written, filing, mechano-graphics, and electronic seriation) has led to a colonization of the speed of change. Rhythms of the natural world (stars, seasons, days, bodily 
functions, heartbeats) are supplemented with rhythms of a human world bound to a technical world in speech, writing, and now coding. Spatial rhythms of a technically-arranged human world might include airport security checks (Kitchin and Dodge 2009), or quotidian driving experiences (Thrift 2004; Sheller 2007; Hind and Gekker 2014). Humans, thus, are orientated toward an industrial space and time that introduces the notion of 'real-time' that forces the human to match the speed of technical evolution, moving as part of a generalized socio-technical system. To put it another way, they are coerced into keeping up with technological evolution.

For the purposes of this chapter, then, the spatial dynamics of contemporary events are co-constituted by the real-time nature of social media platforms. As Leroi-Gourhan suggests:

[t] he individual functions like a cell, an element of the collective program, in a network of signals that not only control his gestures and the process of his effective thought, but which also control his right to absence, that is, to his rest or leisure time [...] Space then exists only as a function of the requirement of time. Socialized time implies a humanized space, integrally symbolic, such that day and night take place in cities at fixed hours [...] and in which the relations between individuals and their place of activity are instantaneous. (1975, 131 as quoted in Stiegler 2009, 89-90)

To return to our story, the construction of the Trojan Horse consisted of multiple tools. Not only the tools for its mechanical construction; the wood and cloth material, the hammers and nails that secure it together, or the paint and brushes that help carry its message, but also the tools of an 'evental' construction (Shaw 2012), or what Stiegler $(2009,115)$ calls "event-ization." These included the messages sent by Sukey, the TUC, and CO11. Each message either directly or obliquely referred to the same Trojan Horse (an 'effigy' or 'incident'). A horse thus made by combining wood, cloth, hammers, nails, paint, brushes, and people, but also a horse made by the organizational accounts of Sukey, the TUC, and CO11. This was a horse constructed by a medium and co-opted by a vast array of actors, ostensibly human and technological. A medium restricted in its possible message by an inherent structure ('no more than 140 characters please!'), online protocol (Galloway 2004), and real-time architecture. In other words, it is through this selective process of deciding "what happens" (Stiegler 2009, 115) and thus what matters, that the event itself is actually constructed. As Stiegler writes, "[t] he preservation of memory, of the memorable [...] is always already also its elaboration: it is never a question of a simple story of 'what happened"' (Ibid.). 
Despite these restrictions, the messages helped to literally orientate protesters to the existence of the Trojan Horse, and did so through the programmatic tendencies of the tool. Furthermore, the Trojan Horse was constituted in space and time by the digital platform, allowing not only debate and discussion, but also physical action to take place. Real-time updates facilitated the navigation of protesters to the Trojan Horse's position. Transforming the space in which to rally around, whether positioned outside the home of David Cameron, or in Oxford Circus. Either as a political object for directing anger at anti-austerity measures or as a (literally) burning, symbolic reminder of the inequalities of capitalism. In other words, the program helped to structure the Trojan Horse, the urban space, and the event for which it was constructed.

\section{Tactility and event}

[U]nder conditions when those with cameras or Internet capacities are imprisoned or tortured or deported, then the use of the technology effectively implicates the body. Not only must someone's hand tap and send, but someone's body is on the line if that tapping and sending gets traced. - Butler (2011, n.p.)

To understand how the spatio-temporal mechanics of a digitally mediated protest event are utilized, we must consider the tactility of such action. This is where we must make a break from Stiegler and instead turn to the work of those most interested in the haptic nature of technology, as well as those furthering a more phenomenological approach to bodily movement. If, as Frith contends, it is through the interface of the mobile phone that "the individual is able to exert control over signifiers and construct a semi-narrative out of the fractured city streets" $(2012,140)$, then what does this mean for a type of protest predicated on solidarity, togetherness, and symbolic holism? Moreover, from a bodily perceptive, how are our senses being retuned to adapt to these kind of hybrid, interfacial instances?

In a world dominated by 'occularcentrism,' as Jay (1994) famously noted, conceptions of touch have been largely neglected. There are numerous types of touch, however, and we are only concerned with one here, at least for the purposes of this chapter. If we are to make a rather academic distinction between 'close' and 'deep' touch then we might say that one 'touches' us, quite literally as in body to body, but we might also say that one 'touches us' emotionally and metaphorically. 'Tactility' is the former; a cutaneous 
sensing of body to body. A form of sensing that relates primarily to the skin "as a sense organ" (Paterson 2007, ix). One particular appendage is most closely connected to the notion of touch, namely the hands. Like the eyes that work as the primary visual organ, so the hands work as contact points for the human body engaging with the world through touching and feeling. ${ }^{3}$

How can tactility help people to orientate themselves? A hypothetical problem posed by philosopher William Molyneux to John Locke in 1690 asked whether an individual born blind and taught to distinguish between two differently shaped objects by touch could do the same by sight alone should they be able to see. The empirical psychologist Marius von Senden (1960) believed that the visual senses had a monopoly on spatial representation, arguing therefore that the blind had no spatial faculties at all since this was solely a preserve of the visual sense. This was to do with Von Senden's insistence that perception was not, what is now called, 'inter-modal.' In other words, the different senses (touch, vision, etc.) would interact with each other through a transcendental perceptual system. Fellow psychologists Gibson (1950), Piaget (1955), and Jones (1975), however, systematically refuted the claim that without sight people lack any spatial cognition whatsoever. They understood perception to be an inter-modal process constituting a "mutually supportive system of the senses" (Paterson 2007, 40). Touch can help mould spatial form, knowledge and experience as much as the visual, and this data can inform, and can be informed by, any of the other senses.

In a traditional sense, orientation concerns our ability to reference waypoints or landmarks like a hill walker might do. In Stieglerian (2009) terms, orientation refers to the openings and affordances we grant to our interaction with technology and the world-at-large. The former is a kind of orientation focused on a distanced vision, a view of far-away reference points that can help to ground the individual, situate their body and place their actions. The latter is employed by Stiegler (2009) to make a more general point about the transformative nature of referencing one particular technological assemblage instead of another. For instance, say, in purposing dominant social media platforms (Twitter, etc.) for a particular need, rather than using outdated machines that fail to carry out the required task as quickly or efficiently as possible (semaphore lines, Morse code, telephones, etc.).

3 Of course, the feet are also another appendage associated with notions of touch, especially in regard to walking. As I primarily wanted to explore the connections between prehensility and technology, and related fieldwork involved the operation of a mobile phone device, I felt I should narrow my focus to include only the hands. Although I do not detail the many ways in which walking is an embodied and haptic experience in this chapter, Ingold (2004), Solnit (2006), and Ingold and Vergunst (2008) provide useful introductions. 
Touch, however, is a 'near-view' orientation, an 'egocentric' (Kitchin, Blades, and Golledge 1997, 233) spatiality that places the subject at the center of the map. This 'performative cartography' (Verhoeff 2012, 13) is opposed to the distancing nature of the visual. In a sense, new digital technological apparatuses allow us to manipulate content like never before. The ability to pore over, stretch, zoom, and pan across objects is in stark contrast to the way in which modern inventions of the panorama, the arcade, the world exhibition, and the plate-glass shop window facilitated the "visual spectacle alone" (Pickles 2000, 9). Tactile interaction is thus, arguably, the primary orientation of contemporary digital society; marking a rather radical shift from phantasmagorical fetishes of the modern era. It is this 'double-tap' philosophy (Hind and Lammes 2015) that drives our interaction with the world and its phenomena.

What does this say about the spatiality of protest as wired through a multitouch mobile device? The mobile smartphone market is now dominated by devices with large, slate-sized screens. Handsets made by Apple, Huawei, and Samsung give preference to 'multi-touch gestures' over the ubiquitous keypad. We are witnessing a technological transition that is re-constituting the human body in an entirely new way. In a passage that now can be applied to the mobile phone, although originally in reference to high-value desktops and industrial machines, Paterson notes:

Whereas the keyboard is a passive mechanical channel between the computer and user, haptics enables a more active exploration and allows the user not just to see three-dimensional shapes represented on the screen, but also to feel them and interact with them. $(2007,128$, emphasis in original)

This corresponds to Paterson's later analysis of the 'proximal tactile interaction' (Ibid., 129) of new haptic technologies. Multi-touch phones allow the user to bridge the distance between visual data and the self, and instead interact with it via cutaneous sensing. This is, arguably, how protesters have sought to comprehend the rather overwhelming size, symbolism, and aims of collective action in the digital age.

A stream of near-live updates from a Twitter account straight to a mobile device gives the protester an ability to calibrate their place in the greater narrative and the wider spatio-temporal extent of the event. Take Sukey, the protest application mentioned previously, which when deployed during demonstrations displayed a digital map replete with the location of essential services for protesters (first aid tents, legal advisors, toilet facilities, WiFi) as well as the shifting points of conflict during a march (police lines, 


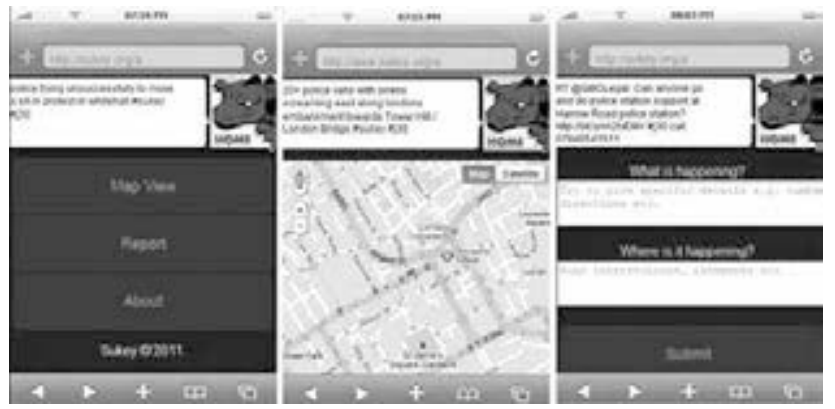

15.2: The Sukey application homepage (left), map view (center) and incident submission form (right) as it was in 2011. Twitter updates are displayed in the box above each screen (author screenshots).

mounted officers, riot vans, a containment), thus allowing users to make navigational decisions (see Figure 15.2). The multi-touch gestures involved in navigating such devices thus enable the protester to be present and 'of the moment.' The egocentric orientation of touch is intertwined with the growing individualization, processual and 'event-centered' framing of mapping, all central to the use of mobile devices during protest events (see Brown and Laurier 2005; Kitchin and Dodge 2007; Perkins 2009). With this combination users are central pivots for navigational duties. Tactile interaction allows events to be brought back to the body itself.

\section{Conclusion: What tools for which citizens?}

Let us return to the pertinent question concerning technological determinism posed by Gerbaudo (2012) earlier: "Is this all just an activist delusion?" The answer, following the analysis in this chapter, should be a qualified no. But, as above, we must continue to steer clear of a technological fetishism that proposes that all and everyone is under the universal spell of technological evolution. The question that remains from this analysis-and one that should replace Gerbaudo's above-is: what tools are appropriate for which citizens? In other words, having hopefully exemplified how digital technology plays a critical role in augmenting protest events, the question of whether their involvement is but a 'delusion' should be answered. Instead, we need to evaluate the extent to which particular technologies can and do generate political power for activists around the world.

In this chapter, I have proposed, through a reading of Stiegler (1998, 2009) and those working at the interface of phenomenological thought and technology, that there are three notable dynamics that come to 
constitute contemporary shifts in protest action. Changes are occurring in our ability to remember, which although not new, is now happening in near real-time. Material devices are providing an instantly referable archive of events that outstrip human capacities. Changes are also being witnessed in our ability to orientate toward real-world incidents. These affordances allow us to be attentive to happenings outside our immediate sensory field. But it is only through a shift to a 'double-tap' philosophy (Hind and Lammes 2015) that allows this to become a reality. The haptic capabilities of the digital device allow us to interact with, manipulate, and re-constitute our worlds. The modernist distancing of the visual is no longer applicable. As the quotes from Judith Butler have iterated throughout this chapter, we must consider how such advancements have created a new co-constructive, hybrid space where citizens are being forced to re-learn their position in the world in order to make their own voices heard.

\section{Acknowledgments}

Thanks to Sam Smith for permission to use his image of the Trojan Horse. The research leading to these results has received funding from the European Research Council under the European Community's Seventh Framework Programme (FP7/2007-2013) / ERC Grant agreement n 283464 .

\section{References}

Ash, J. 2010. Teleplastic technologies: Charting practices of orientation and navigation in videogaming. Transactions of the Institute of British Geographers 35:414-430.

-. 2012. Technology, technicity, and emerging practices of temporal sensitivity in videogames. Environment and Planning A 44:187-203.

BBC News. 2011. Anti-cuts march: Tens of thousands at London protest. BBC. http://www.bbc.co.uk/news/uk-12864353.

Brown, B., and E. Laurier. 2005. Maps and journeys: An ethno-methodological investigation. Cartographica 40 (3): 17-33.

Buechler, S. M. 1995. New social movement theories. The Sociological Quarterly 36 (3): 441-464.

Butler, J. 2011. Bodies in alliance and the politics of the street. Transversal: A Multilingual WebJournal. http://eipcp.net/transversal/1011/butler/en. 
Carr, N. 2008. Is Google making us stupid? The Atlantic. http://www.theatlantic.com/magazine/archive/20o8/o7/is-google-making-us-stupid/306868.

Costanza-Chock, S. 2012. Mic check! Media cultures and the Occupy Movement. Social Movement Studies 11 (3-4): 375-385.

Crutcher, M., and M. Zook. 2009. Placemarks and waterlines: Racialized cyberscapes in post-Katrina Google Earth. Geoforum 40 (4): 523-534.

Dodge, M., and R. Kitchin, 2005. Code and the transduction of space. Annals of the Association of American Geographers 95 (1): 162-18o.

Elden, S. (2011). V for visibility. Interstitial Journal 1-4.

Frith, J. 2012. Splintered space: Hybrid spaces and differential mobility. Mobilities 7 (1) (February): 131-149.

Gallagher, R., and C. Arthur. 2011. Inside lulzsec: Chatroom logs shine a light on the secretive hackers. The Guardian. http://www.guardian.co.uk/ technology/2011/jun/24/inside-lulzsec-chatroom-logs-hackers.

Galloway, A. 2004. Protocol: How control exists after decentralization. Cambridge, MA: The MIT Press.

Gerbaudo, P. 2012. Tweets and the streets: Social media and contemporary activism. London: Pluto Press.

Gibson, J. J. 1950. The senses considered as perceptual systems. London: George Allen \& Unwin.

Gleason, B. 2013. \#Occupy Wall Street: Exploring informal learning about a social movement on Twitter. American Behavioral Scientist 57 (7): 966-982.

Graham, M., M. Zook, and A. Boulton. 2012. Augmented reality in urban places: Contested content and the duplicity of code. Transactions of the Institute of British Geographers 38 (3): 464-479.

Graham, M. 2013. Geography/internet: Ethereal alternate dimensions of cyberspace or grounded augmented realities? The Geographical Journal 179 (2): 177-182.

Haklay, M. 2013. Neogeography and the delusion of democratisation. Environment and Planning $A 45$ (1): 55-69.

Hind, S., and A. Gekker. 2014. 'Outsmarting traffic, together': Driving as social navigation. Exchanges: The Warwick Research Journal 1 (2): 1-17.

Hind, S., and S. Lammes. 2015. Digital mapping as double-tap: Cartographic modes, calculations and failures. Global Discourse 1-19.

Ingold, T. 2004. Culture on the ground: The world perceived through the feet. Journal of Material Culture 9 (3): 315-340.

Ingold, T., and J. Vergunst, eds. 2008. Ways of walking: Ethnography and practice on foot. Aldershot: Ashgate.

Jay, M. 1994. Downcast eyes: The denigration of vision in twentieth-century French thought. Berkeley, CA: University of California Press. 
Jones, B. 1975. Spatial perception in the blind. British Journal of Psychology $66(4): 461-472$.

Jones, J. 2011. Occupy's V for Vendetta protest mask is a symbol of festive citizenship. The Guardian. http://www.guardian.co.uk/commentisfree/2011/ nov/o4/occupy-movement-guy-fawkes-mask.

Juris, J. S. 2012. Reflections on \#Occupy everywhere: Social media, public space, and emerging logics of aggregation. American Ethnologist 39 (2) (May): 259-279.

Kinsley, S. 2014. The matter of 'virtual' geographies. Progress in Human Geography 38 (3): 364-384.

Kitchin, R., M. Blades, and R. G. Golledge. 1997. Understanding spatial concepts at the geographic scale without the use of vision. Progress in Human Geography 21 (2): 225-242.

Kitchin, R., and M. Dodge. 2007. Rethinking maps. Progress in Human Geography 31 (3): 331-344.

-. 2009. Airport code/spaces. In Aeromobilities: Theory and method, eds. S. Cwerner, S. Kesselring, and J. Urry, 96-114. London: Routledge.

- 2011. Code/space: Software and everyday life. Cambridge, MA: The MIT Press.

Lane Bruner, M. 2005. Carnivalesque protest and the humorless state. Text and Performance Quarterly 25 (2): 136-155.

Leroi-Gourhan, A. 1975 [1964-65]. Le geste et la parole. Vol. 2 Le mémoire et les rhythmes. Paris: Broché.

MacKenzie, A. 2002. Transductions: Bodies and machines at speed. London: Continuum Press.

McTeigue, J. (dir). 2005. Vfor Vendetta. Warner Bros. Film.

MetPoliceEvents. 2011. Please can you continue on the march past the Trojan Horse effigy in Downing Street \#march26 \#TUCnews \#march26march \#Demo2011 \#sukey. Twitter. http://twitter.com/MetPoliceEvents/ status/51634253125009409.

Morozov, E. 2011. The net delusion: How not to liberate the world. London: Allen Lane.

Nunes, M. 2006. Cyberspaces of everyday life. Minneapolis, MN: University of Minnesota Press.

Paterson, M. 2007. The senses of touch: Haptics, affects, and technologies. New York: Berg.

Perkins, C. 2009. Performative and embodied mapping. In International Encyclopedia of Human Geography, eds. R. Kitchin and N. Thrift, 126-132. Oxford: Elsevier. 
Piaget, J. 1955. The child's construction of reality. London: Routledge \& Kegan Paul.

Pickles, J. 2000. Cartography, digital transitions, and questions of history. Cartographic Perspectives 37:4-18.

Pickerill, J., and J. Krinski. 2012. Why does Occupy matter? Social Movement Studies 11 (3-4): 279-287.

Rieder, B. 2012. The refraction chamber: Twitter as sphere and network. First Monday 17 (11). http://www.firstmonday.dk/ojs/index.php/fm/article/ view/4199/3359.

Shaw, I. G. R. 2012. Towards an evental geography. Progress in Human Geography 36 (5): 613-627.

Sheller, M. 2007. Bodies, cybercars and the mundane incorporation of automated mobilities. Social \& Cultural Geography 8 (2): 175-197.

Sicart, M. 2014. Play matters. Cambridge, MA: The MIT Press.

Simondon, G. 1958/1980. On the mode of existence of technical objects. Trans. N. Mellamphy. London, ON: University of Western Ontario.

Solnit, R. 2006. Wanderlust: A history of walking. London: Verso Books.

Stevenson, M. 2013. The Web as exception: The rise of new media publishing cultures. PhD thesis University of Amsterdam.

Stiegler, B. 1998. Technics and time, 1: The fault of Epimetheus. Stanford, CA: Stanford University Press.

- 2009. Technics and time, 2: Disorientation. Stanford, CA: Stanford University Press.

Sukey. 2011. Introducing Sukey. Sukey. http://sukey.org.

Sukeyio. 2011a. Fake Stallions Unite http://twitpic.com/4dg6ij \#sukey \#march26. Twitter. http://twitter.com/sukeyio/status/51599597990187008.

—.2011b. Met are asking people to move on past the Trojan horse at Downing St. Else David can't go out to bring it in. \#FSU \#sukey \#march26\#26march. Twitter. http://twitter.com/sukeyio/status/51634902193541120.

Thatcher, J. 2013. Avoiding the Ghetto through hope and fear: An analysis of immanent technology using ideal types. GeoJournal 78 (6): 967-980.

Thrift, N. 2004. Driving in the city. Theory, Culture \& Society 21 (4-5): 41-59. Verhoeff, N. 2012. Mobile screens: The visual regime of navigation. Amsterdam: Amsterdam University Press.

Von Senden, M. 196o. Space and sight: The perception of space and shape in the congenitally blind before and after operation. London: Methuen.

Zook, M., and M. Graham. 2007. The creative reconstruction of the internet: Google and the privatization of cyberspace and DigiPlace. Geoforum $3^{8}$ (6): 1322-1343. 


\section{About the author}

Sam Hind is a Research Associate in Locating Media at the University of Siegen. His research interests include digital navigation and playful methodologies. As a constituent of this work he is keen to develop a conceptual understanding of what he calls 'disruptive cartography.' In more general terms, his research interests stretch across technology, space, and politics to include an interrogation of risk, calculation, and failure as they manifest themselves in and between such worlds. He is currently investigating the limits and limitations of autonomous vehicle technology. He is the co-author of Playful mapping in the digital age (Institute of Network Cultures 2016) with the Playful Mapping Collective, and co-editor of Time for mapping (Manchester University Press 2018). 